\title{
Quasi-biennial oscillations in the geomagnetic field: Their global characteristics and
} origin

\author{
Ou, Jiaming; Du, Aimin; Finlay, Chris
}

Published in:

Journal of Geophysical Research: Space Physics

Link to article, DOI:

10.1002/2016JA023292

Publication date:

2017

Document Version

Publisher's PDF, also known as Version of record

Link back to DTU Orbit

Citation (APA):

Ou, J., Du, A., \& Finlay, C. (2017). Quasi-biennial oscillations in the geomagnetic field: Their global characteristics and origin. Journal of Geophysical Research: Space Physics, 122(5), 5043-5058. https://doi.org/10.1002/2016JA023292

\section{General rights}

Copyright and moral rights for the publications made accessible in the public portal are retained by the authors and/or other copyright owners and it is a condition of accessing publications that users recognise and abide by the legal requirements associated with these rights.

- Users may download and print one copy of any publication from the public portal for the purpose of private study or research.

- You may not further distribute the material or use it for any profit-making activity or commercial gain

- You may freely distribute the URL identifying the publication in the public portal 


\section{QAGUPUBLICATIONS}

\section{Journal of Geophysical Research: Space Physics}

\section{RESEARCH ARTICLE}

10.1002/2016JA023292

\section{Key Points:}

- The geomagnetic QBO at high latitudes is stronger during LT 00:00-06:00, depending strongly on the geomagnetic activity level

- The multipeaks of QBO show similar characteristics in latitudinal and local time distributions, suggesting they are from a common source

- The geomagnetic QBO is found correlated to solar wind parameters and due to the solar wind-magnetosphere-ionosphere coupling process

Correspondence to:

A. Du,

amdu@mail.iggcas.ac.cn

\section{Citation:}

Ou, J., A. Du, and C. C. Finlay (2017), Quasi-biennial oscillations in the geomagnetic field: Their global characteristics and origin, J. Geophys. Res. Space Physics, 122, 5043-5058, doi:10.1002/2016JA023292.

Received 6 AUG 2016 Accepted 8 APR 2017 Accepted article online 12 APR 2017 Published online 8 MAY 2017

\section{Quasi-biennial oscillations in the geomagnetic field: Their global characteristics and origin}

\author{
Jiaming $O u^{1}$, Aimin $\mathrm{Du}^{1}$, and Christopher C. Finlay ${ }^{2}$ \\ ${ }^{1}$ Key Laboratory of Earth and Planetary Physics, Institute of Geology and Geophysics, Chinese Academy of Sciences, Beijing, \\ China, ${ }^{2}$ Division of Geomagnetism, DTU Space, Technical University of Denmark, Lyngby, Denmark
}

Abstract Quasi-biennial oscillations (QBOs), with periods in the range 1-3 years, have been persistently observed in the geomagnetic field. They provide unique information on the mechanisms by which magnetospheric and ionospheric current systems are modulated on interannual timescales and are also of crucial importance in studies of rapid core field variations. In this paper, we document the global characteristics of the geomagnetic QBO, using ground-based data collected by geomagnetic observatories between 1985 and 2010, and reexamine the origin of the signals. Fast Fourier transform analysis of second-order derivatives of the geomagnetic $X, Y$, and $Z$ components reveals salient QBO signals at periods of $1.3,1.7,2.2,2.9$, and 5.0 years, with the most prominent peak at 2.2 years. The signature of geomagnetic QBO is generally stronger in the $X$ and $Z$ components and with larger amplitudes on geomagnetically disturbed days. The amplitude of the QBO in the $X$ component decreases from the equator to the poles, then shows a local maximum at subauroral and auroral zones. The QBO in the $Z$ component enhances from low latitudes toward the polar regions. At high latitudes (poleward of $50^{\circ}$ ) the geomagnetic QBO exhibits stronger amplitudes during LT 00:00-06:00, depending strongly on the geomagnetic activity level, while at low latitudes the main effect is in the afternoon sector. These results indicate that the QBOs at low-to-middle latitudes and at high latitudes are influenced by different magnetospheric and ionospheric current systems. The characteristics of the multiple peaks in the QBO range are found to display similar latitudinal and local time distributions, suggesting that these oscillations are derived from a common source. The features, including the strong amplitudes seen on disturbed days and during postmidnight sectors, and the results from spherical harmonic analysis, verify that the majority of geomagnetic QBO is of external origin. We furthermore find a very high correlation between the geomagnetic QBO and the QBOs in solar wind speed and solar wind dynamic pressure. This suggests the geomagnetic QBO primarily originates from the current systems due to the solar wind-magnetosphere-ionosphere coupling process.

\section{Introduction}

Oscillations with periods in the range 1-3 years had been identified in a wide range of solar, geophysical, geomagnetic, and atmospheric observables and are collectively referred to as quasi-biennial oscillations or QBOs [see, e.g., Bazilevskaya et al., 2014; Baldwin et al., 2001; Sakurai, 1979; Reed et al., 1961, Reed, 1965; Elias and Zossi de Artigas, 2008]. Here we focus our attention on signals with periods of 1-3 years observed in the geomagnetic field, which we refer to as the geomagnetic QBO. As we will discuss further below, this may comprise signals from several distinct physical processes, modulated by a common source.

The geomagnetic QBO was reported early by Kalinin [1954] in a study of the $H, D$, and $Z$ field components. In another influential study, the QBO signals in ground-based observatory data from equator and high latitudes were analyzed in frequency domain [Stacey and Westcott, 1962]. Early studies on the QBO signals were mainly based on the spectral analysis. The geomagnetic QBO was confirmed in the time domain over 1900-1970, based on analysis of the observatory $H$ components [Sugiura, 1976]. The existence of the QBO was also reported in the geomagnetic $S q$ field under the equatorial electrojet [Rao and Joseph, 1971]. By examining the temporal-spatial features, a westward progression of a quasi-biennial wave as well as an association between the equatorial electrojet and the QBO were confirmed. Olsen [1994] presented evidence of a 27 months (2.25 years) oscillation in the low-latitude geomagnetic daily variation. Fraser-Smith [1972] studied the spectrum of the geomagnetic activity index $A p$ and found several lines within the QBO period range (e.g., 1.09 years and 1.47 years). Similarly, Delouis and Mayaud [1975] detected a significant line of 1.44 years in aa index. A peak of 1.4 years was also found in the power spectrum of the auroral occurrence frequency [Silverman and Shapiro, 1983]. 
The geomagnetic QBO presents multiple peaks of periodicity and specific local time behavior. Besides the earlier detected geomagnetic fluctuations of 26-27 months ( 2.2 years [e.g., Stacey and Westcott, 1962]), a number of lines between 2 and 3 years were identified by using maximum entropy spectral analysis on the annual means series from 49 observatories [Currie, 1973]. Kane [1997] conducted spectral analysis on aa index over 1868-1994, showing several peaks within the range 2-4 years (2.00, 2.15, 2.40, 2.70, 3.20, and 3.40 years). Rangarajan [1985] proceeded to analyze the QBO in the Indian zone. He found local time dependence in the disturbance field, being stronger in the evening hours and weaker at noon. Apostolov and Letfus [1988] pointed out other characteristics of the geomagnetic QBO in the aa index, which has a basic period of 25.6 months ( $~ 2.13$ years), and a longer-term modulation of 22 years, with a time varying amplitude and a delayed phase compared to the solar cycle.

Already in early studies, The QBO signals were considered to be related to solar variations. For example, Yacob and Bhargava [1968] found a similar 26 month oscillation in both the equatorial geomagnetic data and the relative sunspot number. Through comparisons to sunspot number and $F_{10.7}$ solar flux, Sugiura [1976] suggested the QBO in the geomagnetic field is produced by the Sun. Sugiura and Poros [1977] reported a time delay between the QBO in the Dst index and that in the sunspot number. They pointed that the observed QBO may be caused by solar modulation of the rate of the plasma injection into the magnetosphere. Today, studies of the QBO phenomenon in solar activity and the related interplanetary parameters are well developed [e.g., Howe et al., 2000; Mursula and Vilppola, 2004; Bazilevskaya et al., 2014, 2016; Kudela et al., 2002; Laurenza et al., 2009].

The QBO in geomagnetic activity has been associated with the QBO of the solar wind parameters and solar heliosphere magnetic field in many recent studies. Paularena et al. [1995] report similar periodicity at 1.3 years in Ap index and solar wind speed. Kane [1997] found a good match between the QBO in aa variations and similar variations in solar wind. Kane [2005] examined the QBO in solar, interplanetary, and terrestrial parameters. Their features, e.g., peak of period, occurrence time, and spectral structure, were compared and discussed. Mursula and Zieger [2000] studied a 1.3 year variation in solar wind speed at $1 \mathrm{AU}$, and its relation to the same periodicity observed in geomagnetic activity and aurorae occurrence. They found a shorter period of variation ( 1.3 years) occurring during even solar cycles, while there was a longer periodicity (1.5-1.7 years) during odd cycles. These QBO signals have been attributed to the evolution of coronal holes and solar dynamo strength [Mursula et al., 2003; Mursula and Vilppola, 2004]. The intermittent appearance and the coupling from the Sun to the Earth of the QBO at 1.3 years has also been discussed [Ruzmaikin et al., 2008]. The intermittent periodicities of QBO have also been observed and verified by the use of wavelet analysis on various solar wind parameters and geomagnetic indices [Katsavrias et al., 2012].

Although the main characteristics of the geomagnetic QBO, including its multiple periodicities and local time preferences, have already been revealed, a systematical analysis and comparisons among different quasi-biennial periods as a function of location, as well as a discussion in the context of ground observatory data used in internal geomagnetic field modeling, have been lacking.

An improved characterization and understanding of the geomagnetic QBO is now a pressing issue for scientists studying the internal geomagnetic field and variations of the underlying dynamo process in the Earth's core. Studies of core field secular variation are increasingly focused on subdecadal timescales thanks to the availability of high-quality magnetic satellite data in recent years, especially from the CHAMP and Swarm missions [e.g., Lesur et al., 2008; Olsen et al., 2015]. Two phenomena of primary interest are a 6 year oscillation thought to be related to torsional Alfven waves within the core [Gillet et al., 2010] and geomagnetic jerks. The latter are abrupt changes in the second time derivative (secular acceleration) of the field that occur on a timescale of 1-2 years or less. In era of satellite observations, geomagnetic core field models are able to resolve internal signals with short timescales, especially at middle and low latitudes, but it is still difficult to completely separate out all external field effects [Langel et al., 1980; Finlay et al., 2016]. For example, a global quasi-biennial fluctuation was identified in a geomagnetic core field model [Silva et al., 2012]. Silva et al. found a sharp peak at approximately 2.5 years in the power spectrum of the global secular acceleration (SA) in the radial component $\left(B_{r}\right)$, predicted by the CHAOS-3 model over 1997-2010. This fluctuation was found to be due to an oscillation of the axially dipolar part of the SA. This may be a signature of an external signal remaining in the core field, although an internal origin could not be ruled out. An improved characterization of the geomagnetic QBO, and a better understanding of its generating mechanism, would be of great 


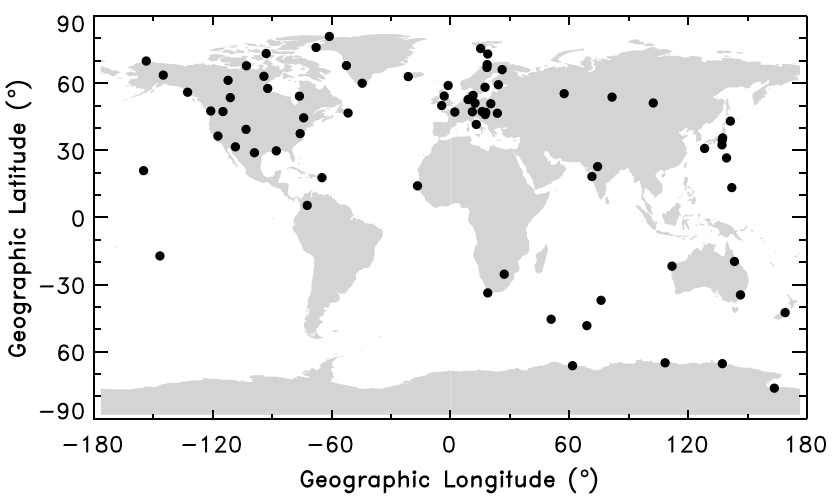

Figure 1. Spatial distribution map of the geomagnetic observatory sites. help to internal field modelers in their efforts to isolate the core field signal, for example, through the development of improved data selection criteria.

The modern global network of geomagnetic ground-based observatories, with high-quality data available from the Word Data Centers (WDC), provides the opportunity to carry out a new characterization of the geomagnetic QBO including its variations with geomagnetic latitude and local time. Advantage can now also be taken of the ready access to a large number of solar wind parameters and geomagnetic activity indices, enabling tests to be carried out regarding possible underlying mechanism of the geomagnetic QBO signals. In this paper, we investigate the QBOs in the observatory monthly means of the $X, Y$, and $Z$ components of the geomagnetic field spanning 1985-2010. Fast Fourier transform (FFT) analysis and wavelet analysis are used to detect and identify the QBO. We then carry out spherical harmonic analysis of the amplitude of the $\mathrm{QBO}$, in order to verify that it is indeed primarily due to external sources. The data sets and basic results are introduced in section 2 where the amplitude distribution of the geomagnetic QBO as a function of geomagnetic latitude and local time are reported. In section 3 we discuss the possible sources of the QBO signals. Section 4 provides conclusions and a discussion of the implications of our findings.

\section{Data Analysis and Results}

\subsection{Data}

We employ the observatory hourly means database from the World Data Center for Geomagnetism, Edinburgh (WDC). The geographical sites of the observatories are plotted in Figure 1. In this paper, the $X$, $Y$, and $Z$ components are defined as the north, east, and down components in the geodetic system of coordinates. Following the strategy of Chulliat and Telali [2007], we diagnose discontinuities (baseline jumps) in geomagnetic time series and correct clear baseline changes [Ou et al., 2015]. We calculate the monthly means from the hourly values, in order to reduce the very high-frequency signals. To filter out the long-term variation trend in the geomagnetic field, we take annual differences of monthly means twice to obtain the discrete estimations of second-order time derivatives time series. For the monthly means magnetic component $B$, the first-order time derivatives estimated at the center epoch $t$ are defined as $\dot{B}_{t}=B_{t+6}-B_{t-6}$, then the estimations of second-order time derivatives at the center epoch $t$ are expressed as

$$
\ddot{B}_{t}=\dot{B}_{t+6}-\dot{B}_{t-6}=B_{t+12}+B_{t-12}-2 B_{t}
$$

Finally, the geomagnetic data series from 76 observatories are obtained during the period from 1985 to 2010.

Figure 2 demonstrates the estimation of second-order time series of the $X, Y$, and $Z$ components (i.e., $\ddot{X}, \ddot{Y}$, and $\ddot{Z}$ ) at Newport (NEW, $242.88^{\circ} \mathrm{E} / 48.27^{\circ} \mathrm{N}$ ) observatory, and their accompanying wavelet spectra. For the geomagnetic time series, it clearly illustrates the presence of persistent quasi-biennial oscillations in all field components. The amplitude of the oscillations in $\ddot{X}$ and $\ddot{Z}$ are stronger compared to those in $\ddot{Y}$. The peak-to-peak amplitude of $\ddot{X}$ and $\ddot{Z}$ varies approximately from 10 to $20 \mathrm{nT} / \mathrm{yr}^{2}$ as a function of time. At this latitude it also seems as if the oscillations in $\ddot{X}$ and $\ddot{Z}$ are anticorrelated. There are considerable variations in the period of the oscillation from about 1 to 3 years over the entire time interval.

In the wavelet amplitude spectrum of $\ddot{X}$, where the Morlet wavelet is used, the QBO periodicity is found to vary between 1 and 3 years but is persistently present between 1988 and 2008. Before 1988, interannual variations are obvious at periods of 1.5-2 years and 3.0-4.0 years. From 1988 to 1995 the QBO signals shows broadband periodicities at 1.0-3.5 years, with maximum amplitude at $\sim 2.2$ years. After 1995 there are two recognizable periods of oscillation in the spectrum. We noted that a new digital recording system began 

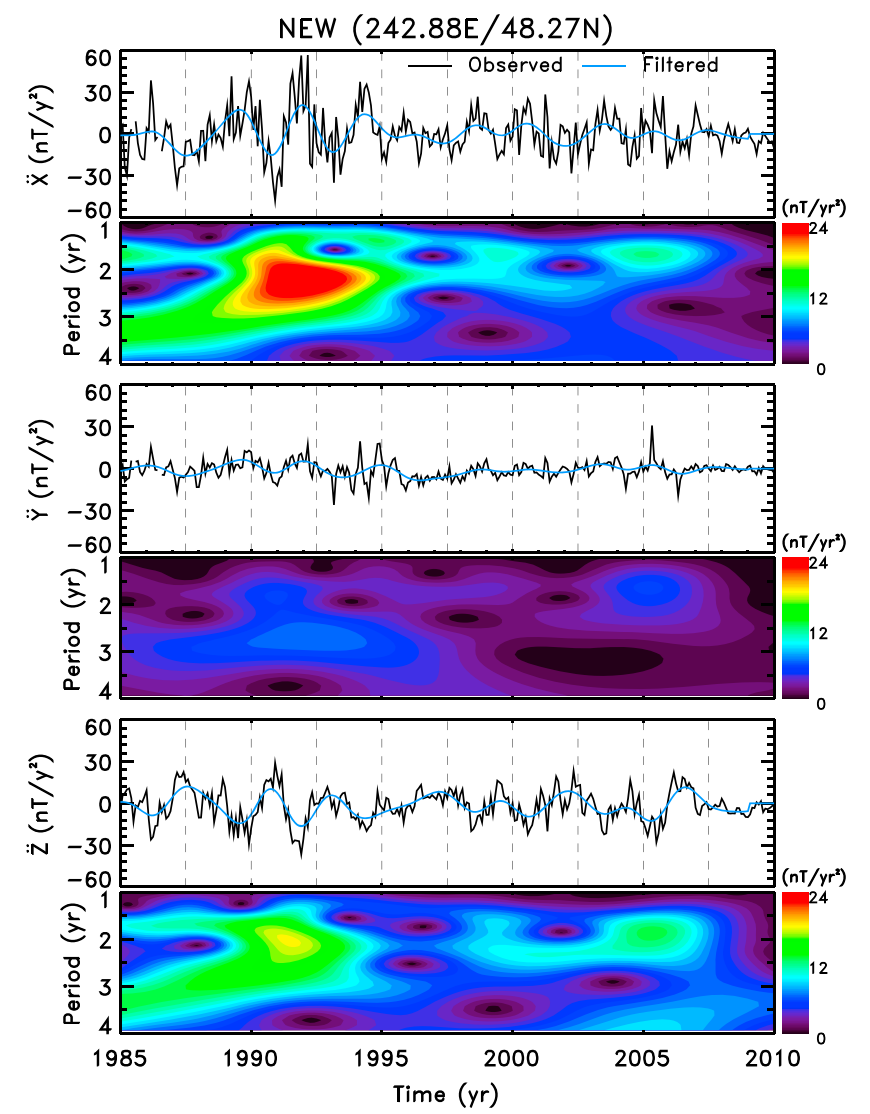

Figure 2. Monthly time series of the second-order time derivatives of the geomagnetic field (from top to bottom, for $\ddot{X}, \ddot{Y}$, and $\ddot{Z}$, respectively) and the corresponding wavelet amplitude spectra over 1985-2010. The monthly time series of are band-pass filtered within the period of $1-3$ years (blue lines).

displayed in Figure 2 illustrates the general characteristics of the $\mathrm{OBO}$ in the geomagnetic field, although the wavelet spectrum does show variations in its amplitude distribution in other observatories and other magnetic field components (not shown in this paper due to limitations of space).

\subsection{FFT Analysis}

To quantify the time-averaged period and amplitude of the QBO in the geomagnetic field between 1988 and 2008, we carried out a fast Fourier transform (FFT) analysis on the observatory monthly means data. In Figure 3 we present the FFT amplitude spectra truncated at a period of 1 year. The grey thin line is the individual spectrum of each observatory, with the black and blue curves being the mean and median values calculated from the individual spectral lines. In $\ddot{X}$, there are five salient peaks at periods of $1.3,1.7$, $2.2,2.9$, and 5.0 years corresponding to the period range of the QBO. The peak at 2.2 years shows the largest amplitude of $\sim 8 \mathrm{nT} / \mathrm{yr}^{2}$ for the individual spectral lines. The amplitude spectrum of $\ddot{Z}$ has similar structure to that of $\ddot{X}$. In detail, the periodicity of 2.2 years of $\ddot{Z}$ exhibits a larger maximum amplitude $\left(\sim 9 \mathrm{nT} / \mathrm{yr}^{2}\right)$, compared to that of $\ddot{X}$. The amplitude of the oscillation over periods of 1-10 years is generally smaller in $\ddot{Y}$ than in $\ddot{X}$ and $\ddot{Z}$. The spectral structures of $\ddot{Y}$ are less consistent among the observatories. The five peaks at periods of $1.3,1.7,2.2,2.9$, and 5.0 years, which are pronounced in the spectra of $\ddot{X}$ and $\ddot{Z}$, are vaguer in $\ddot{Y}$ but still recognizable in the mean spectral line. The maximum amplitude appears at a period of 2.2 years.

Considering the possible origin of the geomagnetic QBO in external field variations, the amplitude spectra of the FFT is tested using various selection criteria for the daily mean data. Figure 4 presents the mean spectra of 

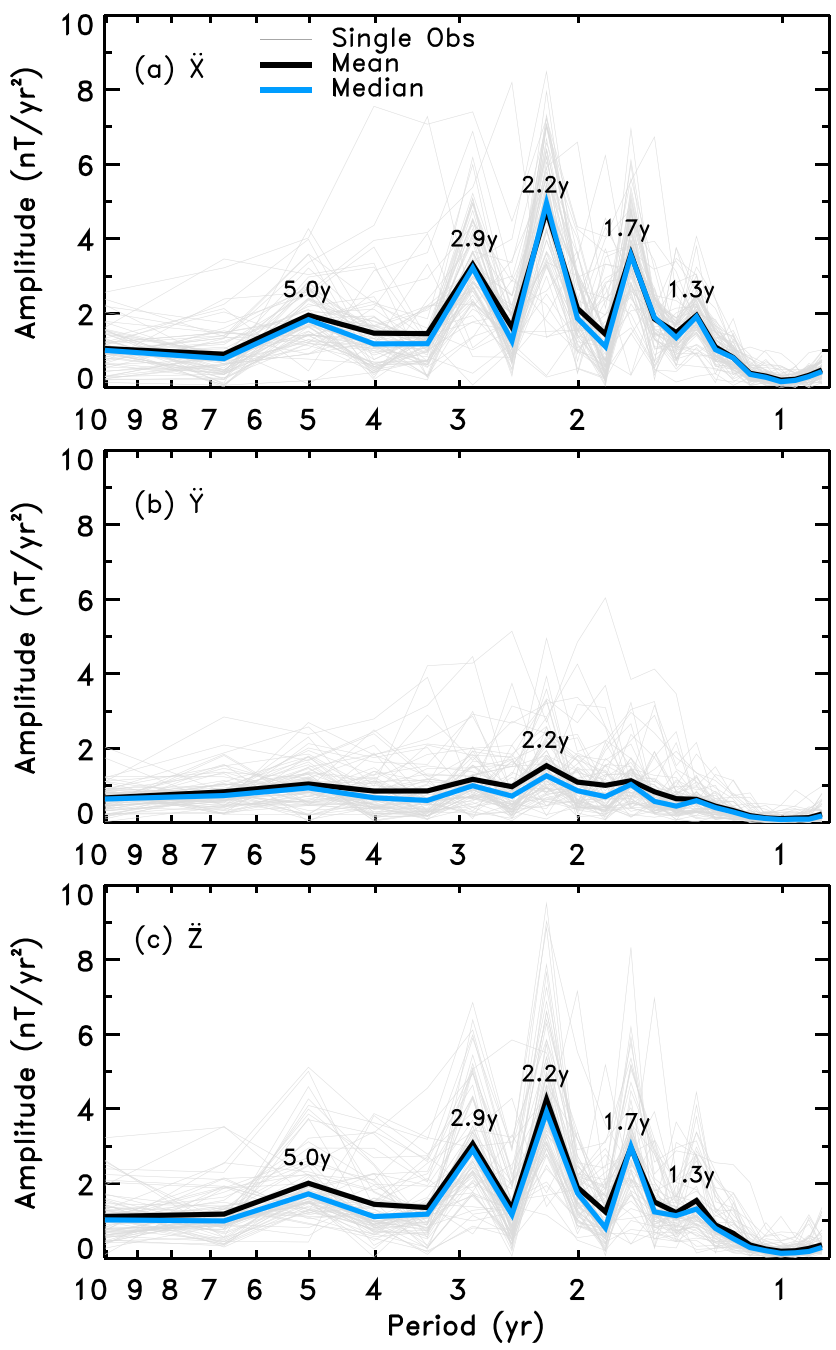

Figure 3. FFT amplitude spectra of the geomagnetic second-order time derivatives over 1988-2008 ((a) $\ddot{X},(b) \ddot{Y}$, and (c) $\ddot{Z})$. The thin grey line is the spectral line at single observatory, and the black and blue thick lines represent the mean and median values of the single spectral lines.

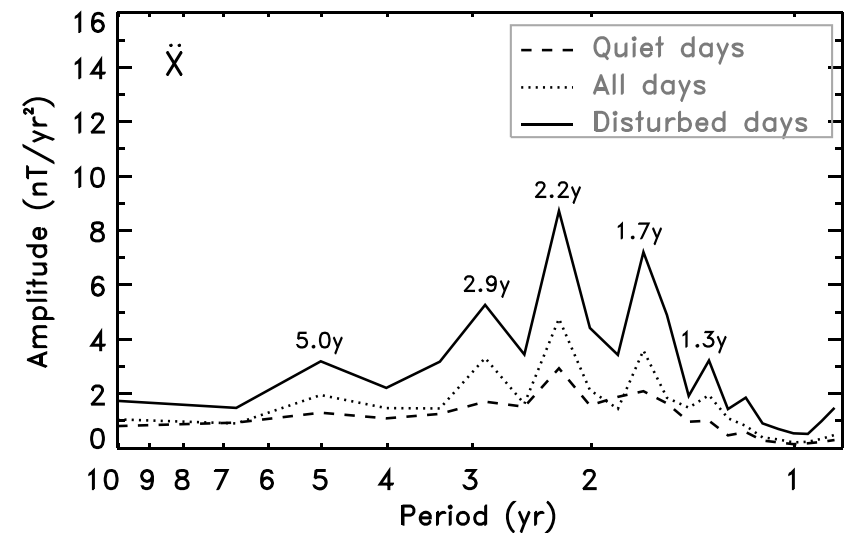

Figure 4. Mean FFT spectral line of $\ddot{X}$ based on the data in international magnetically quiet days (dash line), international magnetically disturbed days (solid line), and all days (dots line).
$\ddot{X}$ based on data from international geomagnetically quiet days (dash line), international geomagnetically disturbed days (solid line), and all days (dots line). The international geomagnetically quiet days and disturbed days for every month are selected by International Service of Geomagnetic Indices (ISGI) based on the $K p$ index. The shapes of the spectral lines for these five data sets are generally similar. On the whole, the QBO amplitude on all days is equivalent to that on quiet days. Major differences are indicated at the periods of 1.3, 1.7, 2.2, 2.9, and 5.0 years, where the amplitude on all days is larger. On quiet days, only the peak at 2.2 years stands out. The spectral line on disturbed days lies completely above that on all days and on quiet days.

The FFT analysis results indicate five clear periodicities in the quasi-biennial range. The highest peak, corresponding to the period of 2.2 years, is prominent in the spectral lines of all field components and under various data selections. The amplitude of the 2.2 year signal in $\ddot{X}$ and $\ddot{Z}$ is much stronger than that in $\ddot{Y}$. The quasi-biennial oscillation in the geomagnetic field is thus certainly closely connected to the amplitude of external geomagnetic disturbances.

\subsection{Spatial and Local Time Dependence of the QBO}

We use the spectral amplitude of the 2.2 year oscillation based on the FFT analysis to represent the amplitude of the geomagnetic QBO for further analysis. In Figure 5, the QBO amplitude at an observatory site (grey dot) is plotted against geomagnetic latitude (the abscissa is the absolute value of latitude, which increases from left to right). To highlight the trend of the amplitude-latitude variation, averaged amplitudes in latitudinal bines of $5^{\circ}$ (beginning from $15^{\circ}$ geomagnetic latitude) are plotted (black dots line). The amplitude distribution in $\ddot{X}$ displays an almost linear descending trend toward higher latitudes $\left(\sim 60^{\circ}\right)$. A maximum is 

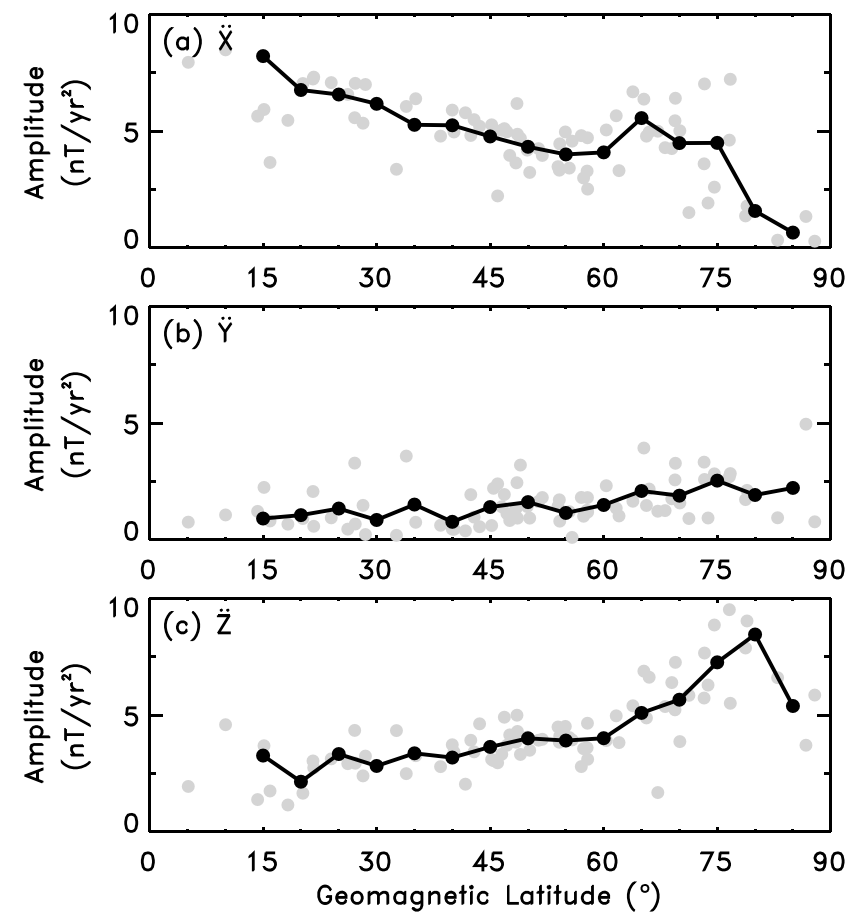

Figure 5. Amplitude of the 2.2 year signal at the observatory sites (grey dots) against absolute geomagnetic latitude based on the FFT analysis ((a) $\ddot{X},(b) \ddot{Y}$, and (c) ZZ). The mean amplitudes over the latitude of every $5^{\circ}$ (begins from $15^{\circ}$ ) are plotted in black dots line.
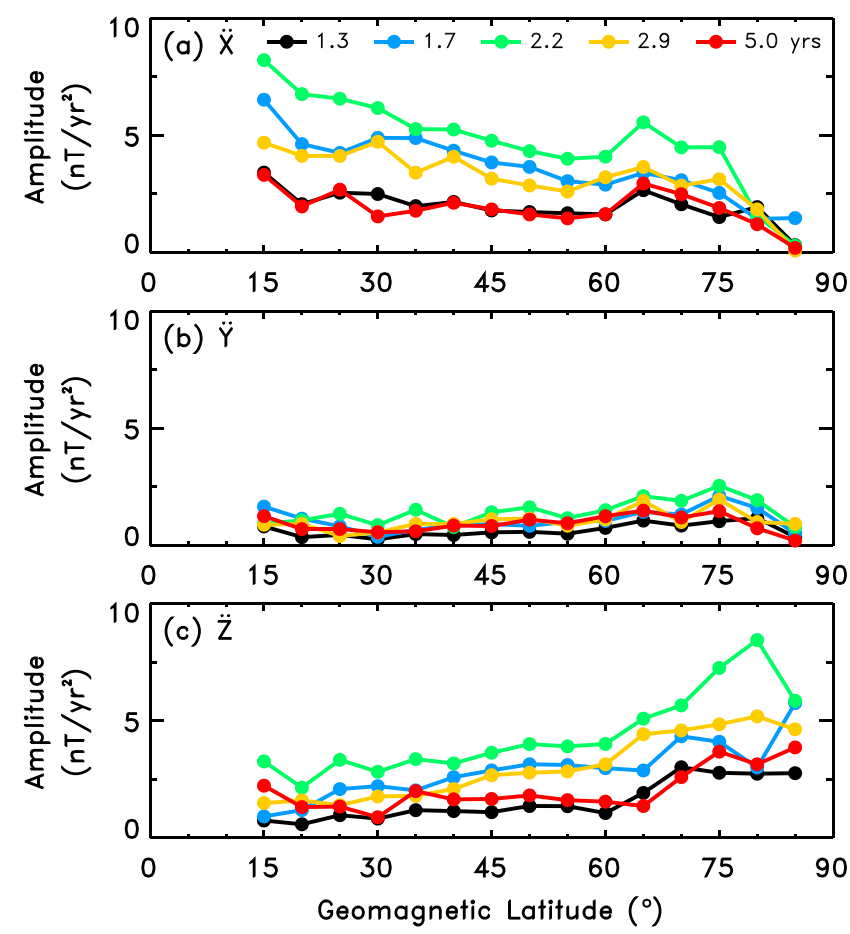

Figure 6. Latitudinal distributions of the $\mathrm{QBO}$ amplitudes at the period of $1.3,1.7,2.2,2.9$, and 5.0 years. The average amplitudes over the geomagnetic latitude of every $5^{\circ}$ are plotted, beginning from the latitude of $15^{\circ}$. seen around the latitudes of $65^{\circ}-75^{\circ}$, which corresponds to the auroral region. In $\ddot{Y}$ the amplitude is rather constant in from the equator to middle latitudes, increases slowly at $40^{\circ}$, and maximizes at $\sim 75^{\circ}$. Contrary to the trends shown in $\ddot{X}$, the amplitude in $\ddot{Z}$ increases from the equator toward high latitudes with a sharper slope at $60^{\circ}$, reaches a maximum value of $10 \mathrm{nT} / \mathrm{yr}^{2}$ at $\sim 75^{\circ}$, and dropping to $5 \mathrm{nT} / \mathrm{yr}^{2}$ in the polar cap regions. It is noted that the amplitude variation at high latitudes (poleward of $60^{\circ}$ ) behaves differently from the linear-like trend shown at low-to-middle latitudes in all components.

The characteristics of multiple peaks in the QBO range (i.e., 1.3, 1.7, 2.2, 2.9, and 5.0 years) are compared in Figure 6. In each panel, the colored dotted lines illustrate the latitudinal distributions of FFT spectral amplitude of different QBO peaks. The dots in every line represent the averaged amplitudes over the latitude in bins of width $5^{\circ}$ (starting from $15^{\circ}$ ). It indicates that the trends of the latitudinal variations for different periodic peaks are similar. In every field component the amplitude of the 2.2 year peak is stronger.

In Figure 7 the pie charts illustrate the local time distributions of the QBO amplitude. The averaged amplitude in different field components (from top to bottom panel) are plotted within different geomagnetic latitude ranges (from the left to right column). In each panel, the local time sectors are divided into $2 \mathrm{~h}$ bins and distributed in a clockwise sequence, beginning at 00:00 from the bottom of the pie. The pies in yellow, blue, and white colors represent the data selected from international geomagnetically quiet days, all days, and disturbed days, respectively. In each sector, the amplitude of individual observatories has been quantified by FFT analysis based on the data from the corresponding local time sector. The radius of the pie slice shows the averaged 2.2 year spectral amplitude 
Latitude: $0^{\circ}-20^{\circ}$
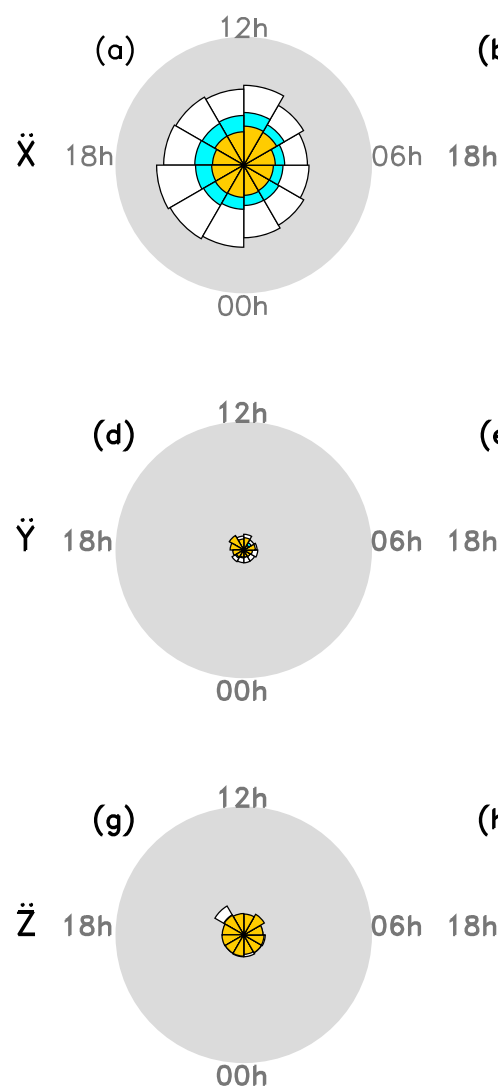

$\nabla$ Quiet days $\nabla$ $20^{\circ}-50^{\circ}$

(b)

$18 \mathrm{~h}$
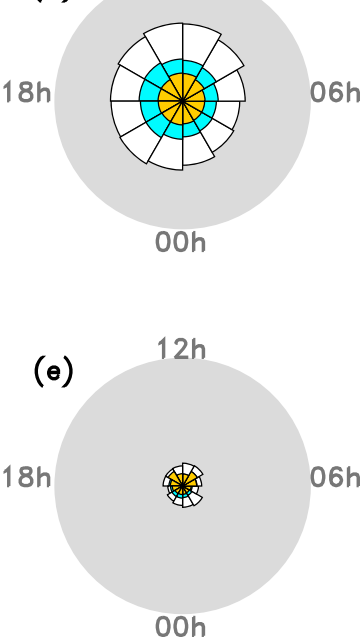

OOh

(h)
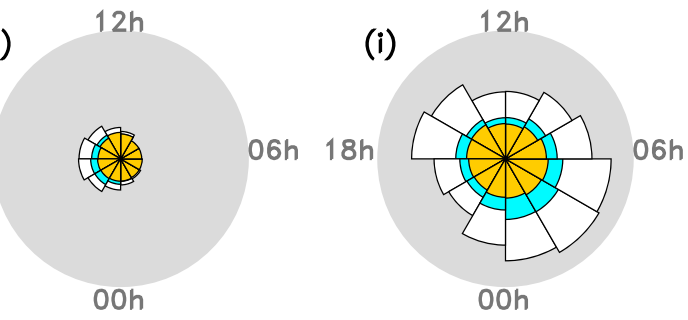

$\nabla$ Disturbed days $8 \mathrm{nT} / \mathrm{yr}^{2}$

Figure 7. Pie charts of the QBO amplitude in the function of local time and geomagnetic latitudes ( $(a-c) \ddot{X},(d-f) \ddot{Y}$, and (g-i) $\ddot{Z}$, for the low (Figures 7a, 7d, and 7g), middle (Figures 7b, 7e, and 7h), and high latitudes (Figures 7c, 7f, and 7i)). The amplitude is represented by the radius of the pie slice. In every panel, the pie slices are plotted with the data on international geomagnetically disturbed days (yellow), all days (blue), and international geomagnetically quiet days.

from the observatories within the chosen latitudinal range. The numbers of observatories at low $\left(0^{\circ}-20^{\circ}\right)$, middle $\left(20^{\circ}-50^{\circ}\right)$, and high latitudes $\left(50^{\circ}-90^{\circ}\right)$ are 6,30 , and 40 , respectively. In each pie, the number of observatories within every local time sector is the same.

On quiet days, the amplitude distribution of the QBO depends little on local time for all any latitudes and in all field components. On all days and disturbed days, the pie slice of $\ddot{X}$ and $\ddot{Z}$ at high latitudes (from $50^{\circ}$ to $90^{\circ}$ ) demonstrates a striking local time dependence in the QBO distribution. The amplitudes in $\ddot{X}$ and $\ddot{Z}$ are relatively larger in the time sector of 22:00-00:00 and 06:00-08:00, and largest during 00:00-06:00. In $\ddot{X}$ the amplitudes during 14:00-18:00 are also relatively larger. In $\ddot{Y}$ the size of the pie slice is smaller than that in $\ddot{X}$ and $\ddot{Z}$. The amplitude is locally smaller during 04:00-08:00 and 12:00-18:00.

At middle latitudes (from $20^{\circ}$ to $50^{\circ}$ ) the amplitudes of $\mathrm{QBO}$ in $\ddot{X}$ and $\ddot{Z}$ are similar, while the amplitude in $\ddot{Y}$ is smaller. $\operatorname{In} \ddot{X}$ and $\ddot{Y}$ the radii of the pie slices are nearly invariant with local time, while in $\ddot{Z}$ the radii in the sector of 14:00-22:00 are larger. This pattern of local time dependence in $\ddot{Z}$ is obvious on all days and on disturbed days. At low latitudes (from $0^{\circ}$ to $20^{\circ}$ ) the QBO is found to be strongest in $\ddot{X}$ and weakest in $\ddot{Y}$. The radii of the pie slices for each field component are similar in all local time sectors on quiet days and considering all days. On disturbed days, the QBO in $\ddot{X}$ shows slightly larger amplitude during 18:00-24:00. It is also shown that the amplitude in $\ddot{Z}$ is locally larger during 20:00-22:00. 

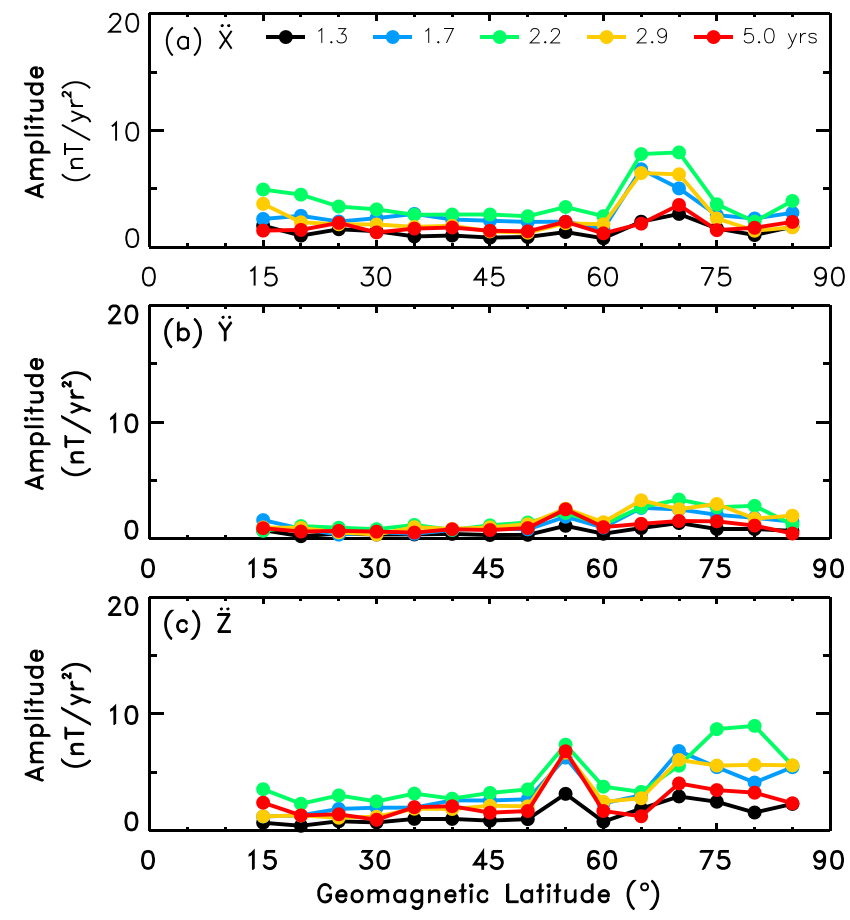

Figure 8. Latitudinal distributions of the $\mathrm{QBO}$ amplitudes at the period of $1.3,1.7,2.2,2.9$, and 5.0 years, with the data selected during $\mathrm{LT}$ 02:00-04:00 on geomagnetically quiet days.
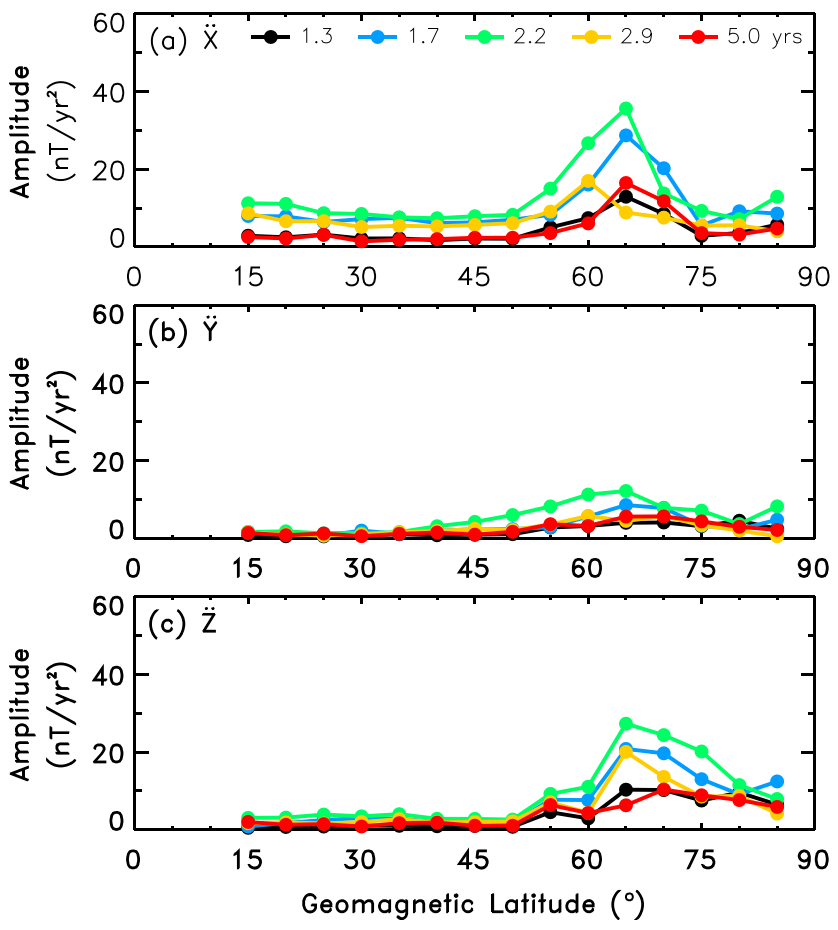

Figure 9. Latitudinal distributions of the $\mathrm{QBO}$ amplitudes at the period of $1.3,1.7,2.2,2.9$, and 5.0 years, with the data selected during $\mathrm{LT}$ 02:00-04:00 on geomagnetically disturbed days.
Figures 8 and 9 show the latitudinal distributions of the QBO amplitudes for multiple peaks over LT 02:00-04:00 on quiet days and disturbed days, respectively. On quiet days (Figure 8 ), the maximum amplitude in $\ddot{X}$ is located around $60^{\circ}-75^{\circ}$ and centered at $65^{\circ}-70^{\circ}$. In $\ddot{Z}$ the amplitude is basically the same at the latitudes poleward of $70^{\circ}$. On disturbed days (Figure 9), the maximum region of $\mathrm{QBO}$ in $\ddot{X}$ spreads down to $50^{\circ}$ and is centered at $65^{\circ}$. In $\ddot{Z}$ a much stronger maximum of amplitude is shifted to be centered at $65^{\circ}$, compared to that on quiet days.

The 2.2 year oscillation, which is the dominant signal in the geomagnetic $\mathrm{QBO}$, clearly depends on geomagnetic latitude and local time, particularly on international geomagnetically disturbed days. The QBO in $\ddot{X}$ is strongest at the equator and attenuates towards high latitudes, while the QBO in $\ddot{Z}$ shows an opposite trend. A local maximum of amplitude is found at the auroral zones in $\ddot{X}$ and at the polar regions in $\ddot{Z}$. In $\ddot{Y}$ the QBO enhances from midlatitudes to the polar regions. The local time dependence of the 2.2 year signal is most prominent at high latitudes. The amplitudes of $\ddot{X}$ and $\ddot{Z}$ are relatively larger in the dawn sector.

\section{Possible Sources of the QBO}

From previous studies and the above analysis, the quasi-biennial oscillations of the geomagnetic field are clearly related to solar activity and solardriven geomagnetic disturbances. In order to analyze the relative amplitude of internal and external contributions to the geomagnetic QBO, we applied spherical harmonic analysis (SHA) model to the amplitude of the 2.2 year variation in the geomagnetic observatory data.In this analysis, the QBO amplitude is presumed to be adequately expressed by the spherical harmonic expansion [e.g., Gauss, 1839; Malin and Hodder, 1982] 

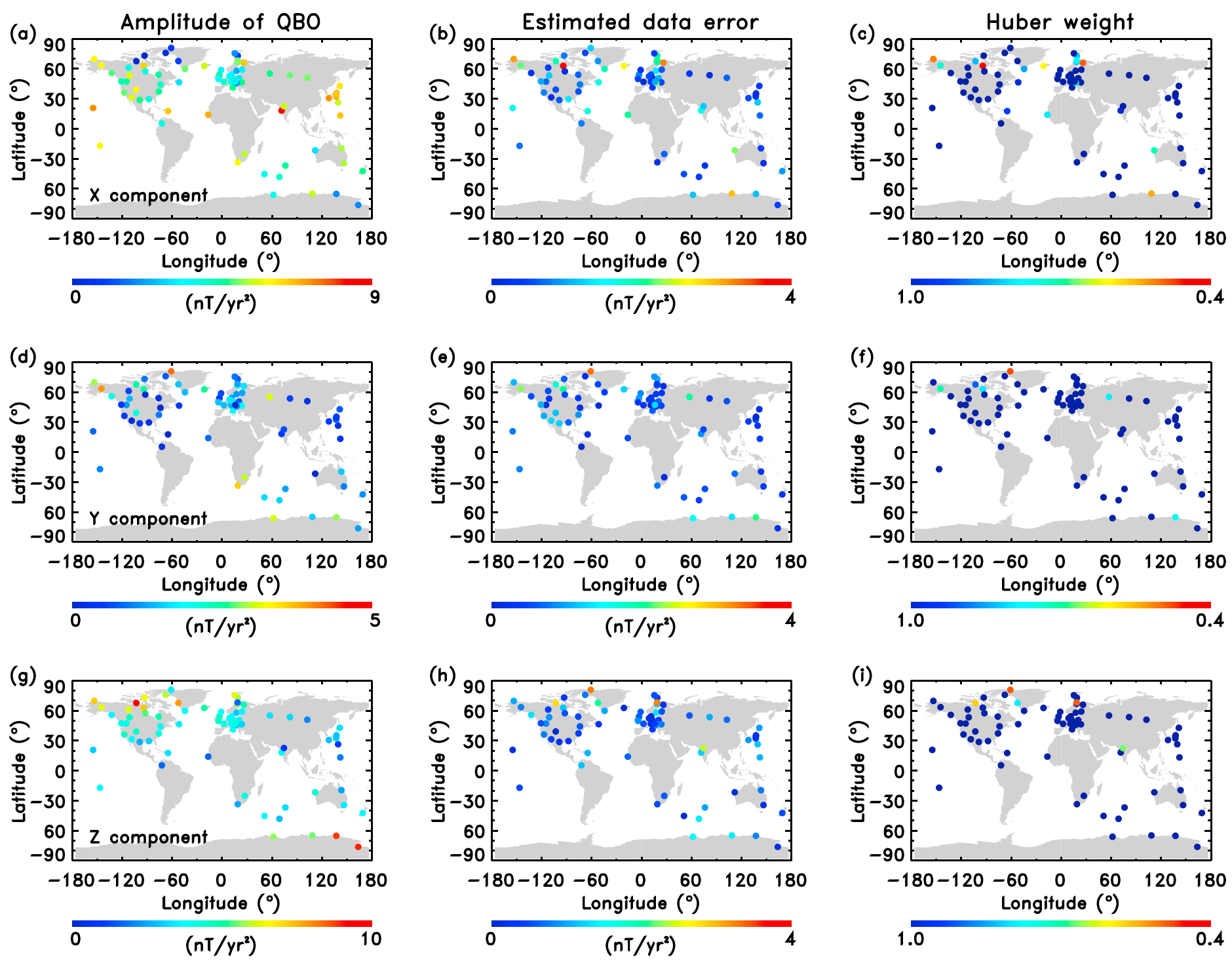

Figure 10. Global maps of (a, d, and g) the QBO amplitudes $A^{\prime},(b, e$, and $h)$ the estimated data residuals, and (c, $f$, and i) the weights used in SH model in the $X, Y$, and $Z$ components (from top to bottom).

$$
\begin{aligned}
A_{X}=A_{X}^{i}+A_{X}^{e}= & \sum_{n=1}^{N^{i}} \sum_{m=0}^{n}\left[\left(\frac{a}{r}\right)^{n+2}\left(g_{n}^{m} \cos m \lambda+h_{n}^{m} \sin m \lambda\right)\right] \frac{\partial P_{n}^{m}(\cos \theta)}{\partial \theta} \\
& +\sum_{n=1}^{N^{e}} \sum_{m=0}^{n}\left[\left(\frac{r}{a}\right)^{n-1}\left(j_{n}^{m} \cos m \lambda+k_{n}^{m} \sin m \lambda\right)\right] \frac{\partial P_{n}^{m}(\cos \theta)}{\partial \theta} \\
A_{Y}=A_{Y}^{i}+A_{Y}^{e}= & \sum_{n=1}^{N^{i}} \sum_{m=0}^{n}\left[\left(\frac{a}{r}\right)^{n+2}\left(g_{n}^{m} \sin m \lambda-h_{n}^{m} \cos m \lambda\right)\right] \frac{m P_{n}^{m}(\cos \theta)}{\sin \theta} \\
& +\sum_{n=1}^{N^{e}} \sum_{m=0}^{n}\left[\left(\frac{r}{a}\right)^{n-1}\left(j_{n}^{m} \sin m \lambda-k_{n}^{m} \cos m \lambda\right)\right] \frac{m P_{n}^{m}(\cos \theta)}{\sin \theta} \\
A_{Z}=A_{Z}^{i}+A_{Z}^{e}= & -\sum_{n=1}^{N^{i}} \sum_{m=0}^{n}\left[(n+1)\left(\frac{a}{r}\right)^{n+2}\left(g_{n}^{m} \cos m \lambda+h_{n}^{m} \sin m \lambda\right)\right] P_{n}^{m}(\cos \theta) \\
& +\sum_{n=1}^{N^{e}} \sum_{m=0}^{n}\left[n\left(\frac{r}{a}\right)^{n-1}\left(j_{n}^{m} \cos m \lambda+k_{n}^{m} \sin m \lambda\right)\right] P_{n}^{m}(\cos \theta)
\end{aligned}
$$



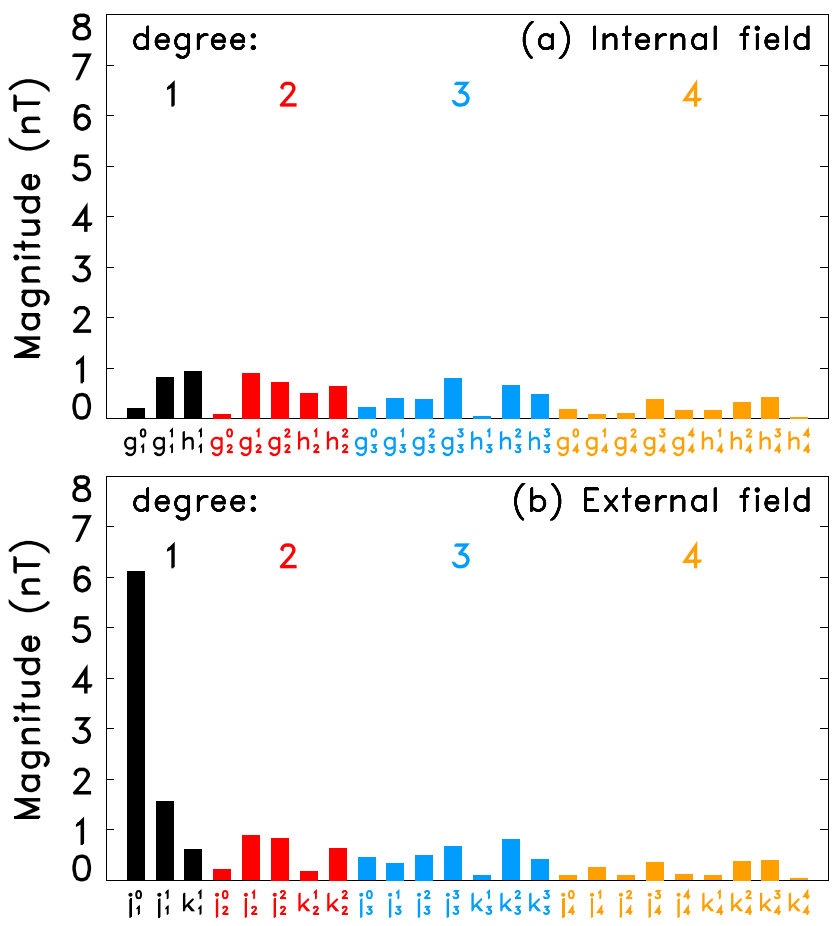

Gauss coefficients

Figure 11. Diagrams of the internal and external coefficients deriving from the $\mathrm{SH}$ analysis, with the model truncation of degree 4. where $\left\{A_{X}, A_{Y}, A_{Z}\right\}$ are the amplitudes of the 2.2 year signal in $\ddot{X}, \ddot{Y}$, and $\ddot{Z}$, respectively; $a=6371.2$ the mean spherical radius of the Earth; $\{\lambda, \theta, r\}$ the longitude, colatitude, and radius in the geographic (geocentric) coordinate system; $\left\{g_{n}^{m}, h_{n}^{m}\right\}$ Gauss coefficients of the internal field; $\left\{j_{n}^{m}, k_{n}^{m}\right\}$ Gauss coefficients of the external field; and $P_{n}^{m}(\cos \theta)$ the associated (Schmidt seminormalized) Legendre functions. The superscripts $i$ and $e$ represent the internal and external parts, respectively.

Note that the input amplitude of the 2.2 year signal should not be in the form of an absolute value, if the phases of the oscillations at different observatory sites are to be considered. From the FFT analysis, the phase of the 2.2 year periodicity is mostly around $60^{\circ}$ in $\ddot{X}$. The 2.2 year signal in the Southern Hemisphere has approximately the same phase in $\ddot{Z}$ and $\ddot{X}$, while in the Northern Hemisphere the phase at a large number of observatories is around $-120^{\circ}$ in $\ddot{Z}$. This implies that in $\ddot{Z}$ the

2.2 year signal is anticorrelated between two hemispheres. To take into account the phase information, the input amplitude of QBO in SH model has been normalized as $A^{\prime}=A \cdot \cos \left(P-60^{\circ}\right)$, where $A^{\prime}$ is the revised amplitude at the period of 2.2 years and $P$ is the phase of the 2.2 year signal calculated by the FFT analysis. Estimation of the model coefficients $\left\{g_{n}^{m}, h_{n}^{m}, j_{n}^{m}, k_{n}^{m}\right\}$ is treated as a linear problem

$$
\mathbf{A}=\mathbf{B X},
$$

where $\mathbf{A}$ is the vector of input amplitude data, $\mathbf{B}$ the interaction matrix, and $\mathbf{X}$ the vector of model coefficients. We use an iteratively reweighted least squares approach, minimizing the chi-square misfit $\chi^{2}=\mathbf{e}^{T} \boldsymbol{W}^{-1} \mathbf{e}$, where the residual vector $\mathbf{e}=\mathbf{A}-\mathbf{A}_{\text {mod }}$ is the difference between the input amplitude vector $\mathbf{A}$ and the model prediction vector $\mathbf{A}_{\text {mod. }}$. We implemented a weight matrix $\boldsymbol{W}$ containing Huber weights, for the purpose of reducing the effect of outliers in the observed data. [see, e.g., Olsen et al., 2006]. The Huber weights are used in the diagonal component $w_{\mathrm{ii}}$ of the weight matrix $\boldsymbol{W}^{-1}$,

$$
w_{\mathrm{ii}}=\min \left(c / \varepsilon_{i}, 1\right)
$$

with $c=1.5, \varepsilon_{i}=\left(A_{\mathrm{obs}, \mathrm{i}}-A_{\mathrm{mod}, \mathrm{i}}\right) / \sigma$, and $\sigma$ the standard deviation of data errors. Therefore, the estimation of Gauss coefficients can be written as

$$
\mathbf{X}=\left(\mathbf{B}^{T} \boldsymbol{W}^{-1} \mathbf{B}\right)^{-1} \mathbf{B}^{T} \boldsymbol{W}^{-1} \mathbf{A}
$$

The model truncation in this analysis is mainly limited by the number of observations and the spatial distribution of the observatory sites (a truncation of degree $N$ will yield $2 N(N+2)$ coefficients, while only 76 observatory data are used in this paper). We tested model truncations from degree 3 to 5 and found that the truncated degree of $4(N=4)$ for both internal and external part gives a good compromise between quality of internal/external separation and robustness of model estimation.

Figure 10 shows the resulting global contribution maps of the QBO amplitude $A^{\prime}$ (left column), the estimated data error (middle column), and the weights used in the model (right column). The estimated data residuals are higher around auroral latitudes in the $X$ and $Y$ component, and at middle and low latitudes in the $Z$ component. Lower weights (red) are correspondingly given to the observatories where their data misfits 


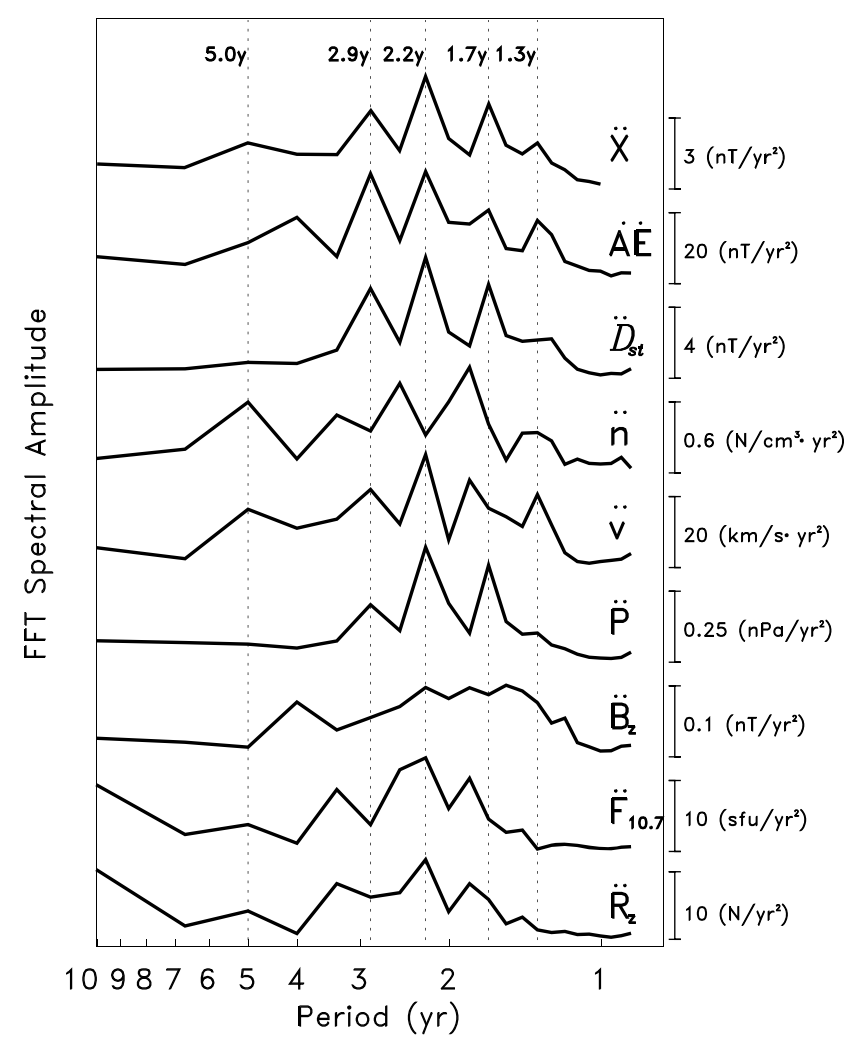

Figure 12. FFT amplitude spectral lines of the parameters in solar activity, solar wind at $1 \mathrm{AU}$, geomagnetic activity, from bottom to top, including the Zurich relative sunspot number $\left(R_{z}\right), F_{10.7}$ solar radio flux $\left(F_{10.7}\right)$, proton density in solar wind $(n)$, solar wind speed $(v)$, solar wind dynamic pressure $(P)$, interplanetary magnetic field of $Z$ component in the GSE coordinate system (IMF $\left.B_{z}\right)$, Dst index (Dst), and $A E$ index $(A E)$, respectively. The mean spectral line of the geomagnetic field in $\ddot{X}$ is also shown at the top. ual variations in solar activity, solar wind, and geomagnetic activity, we next compared the FFT amplitude mean spectral line in $\ddot{X}$ (black thick lines in Figure 3) with the spectral lines of various parameters. We examined the second-order time derivatives of monthly means time series of these parameters, including the Zurich relative sunspot number $\left(R_{z}\right), F_{10.7}$ solar radio flux $\left(F_{10.7}\right)$, proton density in solar wind $(n)$, solar wind speed $(v)$, solar wind dynamic pressure $(P)$, interplanetary magnetic field of $Z$ component in the GSE coordinate system (IMF $B_{z}$ ), Dst index $(D s t)$, and $A E$ index $(A E)$. The data of solar wind parameters at $1 \mathrm{AU}$ and the interplanetary parameters are obtained from the OMNI database of National Space Science Data Center (NSSDC).

Figure 12 shows the FFT amplitude spectral lines for various parameters of solar activity, solar wind at $1 \mathrm{AU}$, and the geomagnetic activity, within the same period range shown in Figure 3, respectively. The mean spectral line of $\ddot{X}$ is also shown in Figure 3a. Salient peaks at the periods of 1.7, 2.2, and 2.9 years are distinctly present in the spectra of $\ddot{P}, \ddot{v}, \ddot{D} s t$, and $\ddot{A E}$, respectively. An additional peak at 1.3 years is recognizable for $\ddot{v}$. The multiple-peak spectral structure, with the highest peak at the period of 2.2 years, is also seen in the amplitude spectrum of the geomagnetic field. For $\ddot{R}_{Z}$ and $\ddot{F}_{10.7}$, only one peak at the period of 2.2 years stands out in their spectra. For $\ddot{n}$ and $\ddot{B}_{Z}$, their amplitude spectra differ significantly from those in the geomagnetic field components.

To further investigate the relation between the geomagnetic QBOs and the QBOs in the solar wind, Figure 13 illustrates the latitudinal distribution of correlation coefficients between the monthly means of the geomagnetic field components $\ddot{X}, \ddot{Y}$, and $\ddot{Z}$ (from top to bottom) and solar wind dynamic pressure $\ddot{P}$. Because the QBO 

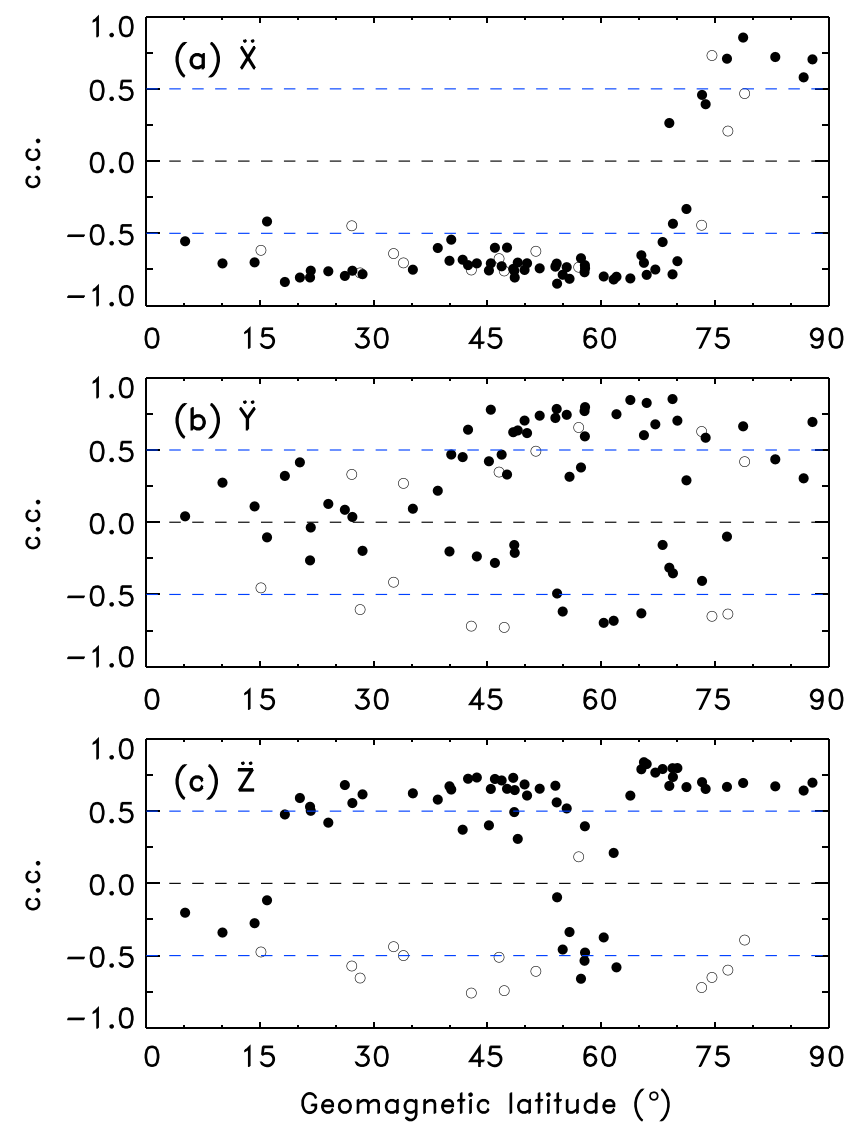

Figure 13. Correlation coefficients between the filtered geomagnetic observatory series and filtered solar wind dynamic pressure against absolute geomagnetic latitude (solid circles represent the observatories in the Northern Hemisphere, and hollow circles for the Southern

Hemisphere). The black dash line indicates the zero level, and the blue dash lines show the correlated level of \pm 0.5 . shown in Figures 13 and 14. For both $\ddot{X}$ and $\ddot{Z}$, the correlations with $\ddot{P}$ are a little higher than those with $\ddot{v}$ at low-to-middle latitudes, while at high latitudes the correlations with $\ddot{v}$ seem slightly higher.

From the results of the spherical harmonic analysis, the quasi-biennial oscillation of the geomagnetic field is confirmed to be primarily of external origin. Through the comparisons of the FFT amplitude spectrum, the geomagnetic QBO bears a strong relation with the variation of solar wind speed and solar wind dynamic pressure at $1 \mathrm{AU}$.

\section{Conclusion and Discussion}

We have investigated in detail the geomagnetic quasi-biennial oscillations (QBOs) by examining the second-order time derivatives derived from monthly means of the $X, Y$, and $Z$ field components from the global network of ground-based observatories between 1985 and 2010. Five salient periods respectively at $1.3,1.7,2.2,2.9$, and 5.0 years have been identified in the resulting amplitude spectra. The oscillation at 2.2 years is found to be the most prominent in all field components. The amplitude of the QBO in $\ddot{X}$ decreases from the equator to high latitudes then shows a maximum in the auroral zones. The QBO in $\ddot{Z}$ increases from low latitudes toward the polar regions. The QBO signals at high latitudes (poleward of $50^{\circ}$ ) seen in $\ddot{X}$ and $\ddot{Z}$ are both stronger for postmidnight local times in the morning sector (LT 00:00-06:00). The characteristics of the multiple peaks in the QBO range are found to be similar in latitudinal and local time distributions, suggesting that these oscillations are derived from a common source. The higher amplitude on disturbed days, the 

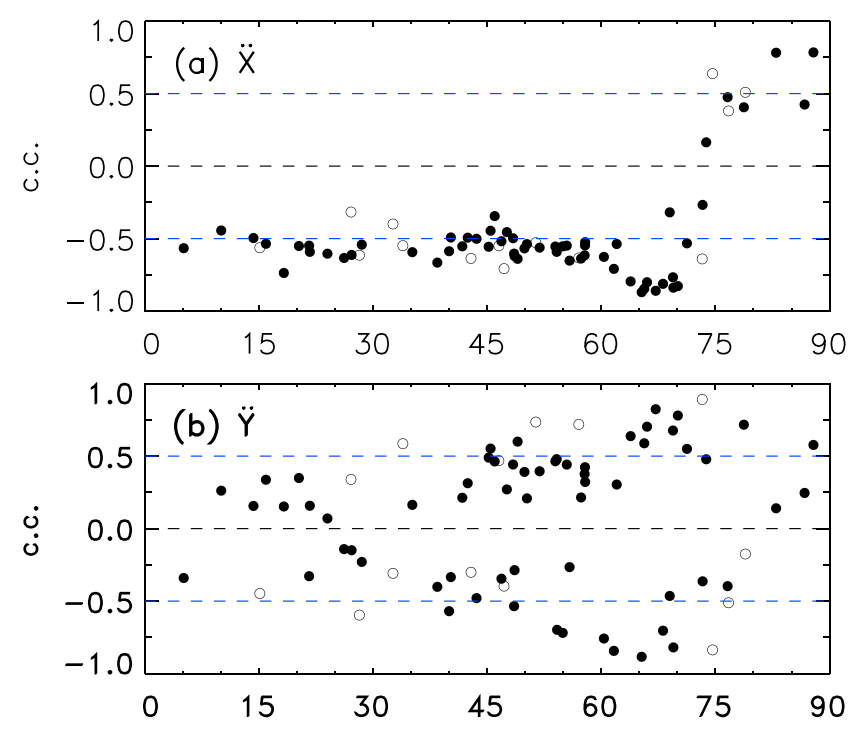

Figure 14. Same caption as Figure 13 but for the correlation coefficients between the filter geomagnetic observatory series and filtered solar wind speed.

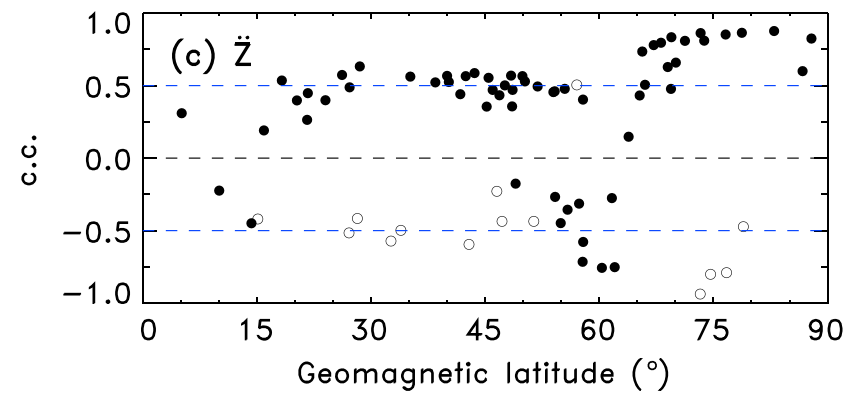

features of local time dependence, and the results from the $\mathrm{SH}$ model confirm that the geomagnetic QBOs can be mainly attributed to external fields. The internal contribution of the QBO signals may perhaps be partly due to the currents induced inside the Earth. Through the correlation analysis, the geomagnetic QBOs are illustrated to be highly correlated with the QBOs in the solar wind speed and solar wind dynamic pressure. The strong signatures of the QBO in the auroral zones may suggest that the enhanced $\mathrm{QBO}$ at high latitudes is a result of the auroral electrojets caused by solar wind-magnetosphere-ionosphere coupling processes.

As shown in Figure 3, geomagnetic QBOs are observed at 1.3, 1.7, 2.2, and 2.9 years in the FFT amplitude spectra. The dominant periodicity at 2.2 years ( 26.4 months) was found in previous studies of the geomagnetic field [e.g., Stacey and Westcott, 1962; Apostolov and Letfus, 1988] and the Sun [Bazilevskaya et al., 2014]. The periods at 1.3 and 1.7 years were often discussed in solar activity, solar wind, and geomagnetic activity [e.g., Kane, 1997; Mursula and Zieger, 2000; Kudela et al.,

2002; Laurenza et al., 2009]. The 2.9 year oscillation was reported but less clearly isolated in previous spectral analysis of geomagnetic field [e.g., Currie, 1973]. In the present paper, the features of the QBO at multiple periods and their latitudinal and local time variations (see Figures 6, 8, and 9) suggest that these oscillations are derived from a common source. In addition, the 1.3 year oscillations are seen more strongly during 1985-1990, and the 1.7 year signals are more clearly observed during 1990-2000 in the wavelet spectra (Figure 2). This spectral structure is consistent with the relative wavelet spectral structure of solar wind speed shown by Mursula and Zieger [2000] (see the top panel of Figure 2 in their paper). As demonstrated in Figures 13 and 14, the correlation coefficients between the geomagnetic field and solar wind parameters are generally higher than \pm 0.5 (within $15^{\circ}-70^{\circ}$ geomagnetic latitude) in the $X$ and $Z$ components. This further suggests that the geomagnetic QBO signals are primarily derived from the current systems controlled by the solar wind-magnetosphere-ionosphere coupling processes [e.g., Lockwood et al., 1999; Stamper et al., 1999; Richardson et al., 2000].

As seen in Figure $5 \mathrm{a}$, the QBO at low-to-middle latitudes (equatorward of $50^{\circ}$ ) is primarily strong in $\ddot{X}$. The amplitude in $\ddot{X}$ decreases from the equator toward subauroral latitudes (Figure 5a). The amplitudes of the QBO in $\ddot{X}$ at low-to-middle latitudes are approximately uniform in their local time distribution (see Figure 7). These features of the geomagnetic QBO at low-to-middle latitudes are coincident with the magnetic variations generated by the symmetric ring current system, which is seen mainly during the recovery phase of geomagnetic storms and quiet days [Jordanova et al., 2003; Le et al., 2004; Zhao et al., 2013]. At lowto-middle latitudes, the higher correlations with $\ddot{P}$ (see Figures $13 \mathrm{a}$ and $13 \mathrm{c}$ ), compared to those with $\ddot{v}$ (Figures 14a and 14c), may imply that the QBO signals here are more sensitive to solar wind dynamic pressure than solar wind speed [Araki and Shinbori, 2016]. Due to the limitations of the observatory distribution, we see no clear signature of equatorial electrojet seen around the equator. The QBO at low-to-middle latitudes 
displays little local time dependence on disturbed days, implying that the signatures originating from ionospheric Sq current system [Xu and Kamide, 2004; Stening, 2008] do not dominate.

The latitudinal variation of the QBO in $\ddot{X}$ clearly shows a maximum around $65^{\circ}-75^{\circ}$ (see Figure $5 \mathrm{a}$ ), which corresponds to the average location of the auroral electrojets [e.g., Kamide and Kokubun, 1996]. Particularly on quiet days, the maximum amplitude of QBO in $\ddot{X}$ is located within $60^{\circ}-75^{\circ}$ and centered at $\sim 70^{\circ}$ (see Figure 8a). On disturbed days, the maximum region spreads down to $50^{\circ}$ and is centered at $65^{\circ}$ geomagnetic latitude (Figure 9a). The changes of the maximum region of the geomagnetic QBO coincide with the behaviors of westward auroral electrojets (WEJ) and eastward auroral electrojets (EEJ) under different geomagnetically disturbed conditions [Ahn et al., 1984, 1989]. As further demonstrated in Figures 13a and 14a, the signs of the correlation coefficients poleward of $\sim 70^{\circ}$ are opposite to those at lower latitudes. This feature may be explained by magnetic variations controlled by WEJ and EEJ being in antiphase in the $X$ component at the auroural zones. Because the estimations of second-order time derivatives are used, the sign of the correlation is unable to distinguish between the directions of WEJ and EEJ. Moreover, in the auroral zones $\left(60^{\circ}-70^{\circ}\right)$ in $\ddot{X}$ (Figure 13a), the correlations coefficients with $\ddot{v}$ are found to be highest. At high latitudes (poleward of $65^{\circ}$ ) in $\ddot{Z}$ (Figure 13c), the correlations with $\ddot{v}$ are relatively higher rather than those with $\ddot{P}$ (Figure 14c). This suggests a closer relationship between the QBO at high latitudes, the auroural electrojets, and solar wind speed [e.g., Mursula et al., 2003; Svalgaard and Cliver, 2007; Lukianova et al., 2012; Holappa et al., 2014]. The QBO at high latitudes (poleward of $50^{\circ}$ ) are found to be enhanced for postmidnight local times in the morning sector (LT 00:00-06:00), especially on disturbed days. Both the latitudinal and local time variations of QBO in the auroral zones correspond to the features of the enhanced WEJ and EEJ in the postmidnight sector during substorms [Kamide and Kokubun, 1996; Ahn et al., 1984; Xu et al., 2008]. As coupling parameters based on the solar wind speed, rather than other parameters in magnetospheric activity, have been shown a much better predictor of onset probability of substorms [Newell et al., 2016], it seems likely that the QBO at high latitudes are mainly controlled by the variations of auroral electrojets.

Both the latitudinal (Figure 5b) and local time (Figures 7d-7f) distributions show that the QBO in $\ddot{Y}$ has much smaller amplitude than that in $\ddot{X}$ and $\ddot{Z}$, especially at low-to-middle latitudes. This suggests that the geomagnetic QBO seem to have little direct connection with the field-aligned currents [e.g., lijima, 2000].

The spherical harmonic analysis on the QBO amplitude confirms the fact that the geomagnetic QBO is primarily of external origin. The energy contributions described by the $\mathrm{SH}$ model in our paper maybe imperfect, due to the uneven distribution of the observatory sites [Olsen et al., 2010] and the limited number of available sites. The model coefficients are, however, verified to be robust through the tests using a range of truncation levels. The contribution from the internal field may be, at least partly, due to induced effects. Note that the energy ratio of external part to internal part in the $\mathrm{SH}$ analysis is larger than in previous studies on the induced field of the geomagnetic activities, such as Sq currents and magnetic storms [e.g., Chapman and Bartels, 1940]. This may be due to a deeper penetration of the induced currents inside the Earth for the external quasi-biennial disturbances. Another possibility that the internal part of the QBO in part results from the Earth's dynamo process cannot be ruled out, because similar periodicities (e.g., geomagnetic jerk occurring in 1-2 years, with the amplitude of several to tens of $\mathrm{nT} / \mathrm{yr}^{2}$ [Mandea et al., 2010]) derived from geodynamo are observed at the Earth's surface. A combined analysis together with ground-based observations and satellite measurements is needed to better separate the internal and external sources of QBO.

The QBO signal seen in some internal field models may possibly be partly due to the leakages of the external disturbance, which now requires close examination. A model to describe the QBO is clearly needed, so as to better isolate the external field from the geomagnetic observations. Data selections and external field modeling strategies adopted by internal field modelers will also need to be reexamined.

\section{References}

Akasofu, S. I. (1981), Energy coupling between the solar wind and the magnetosphere, Space Sci. Rev., 28(2), $121-190$. Ahn, B. H., Y. Kamide, and S. I. Akasofu (1984), Global ionospheric current distributions during substorms, J. Geophys. Res., 89, 1613-1625, doi:10.1029/JA089iA03p01613.

Ahn, B. H., H. W. Kroehl, Y. Kamide, and D. J. Gorney (1989), Estimation of ionospheric electrodynamic parameters using ionospheric conductance deduced from bremsstrahlung X-ray image data, J. Geophys. Res., 94, 2565-2586, doi:10.1029/JA094iA03p02565.

Apostolov, E. M., and V. Letfus (1988), Some characteristics of quasi-biennial geomagnetic oscillations of solar origin, Stud. Geophys. Geod. $32(2), 171-186$. 
Araki, T., and A. Shinbori (2016), Relationship between solar wind dynamic pressure and amplitude of geomagnetic sudden commencement (SC), Earth Planets Space, 68(1), 1-7.

Bazilevskaya, G., A. M. Broomhall, Y. Elsworth, and V. M. Nakariakov (2014), A combined analysis of the observational aspects of the quasi-biennial oscillation in solar magnetic activity, Space Sci. Rev., 186(1-4), 359-386.

Bazilevskaya, G. A., M. S. Kalinin, M. B. Krainev, V. S. Makhmutov, A. K. Svirzhevskaya, N. S. Svirzhevsky, and Y. I. Stozhkov (2016), On the relationship between quasi-biennial variations of solar activity, the heliospheric magnetic field and cosmic rays, Cosm. Res., 54(3), 171-177. Baldwin, M. P., et al. (2001), The quasi-biennial oscillation, Rev. Geophys., 39(2), 179-229.

Chapman, S., and J. Bartels (1940) Geomagnetism, vol. 2, Clarendon Press, Oxford.

Chulliat, A., and K. Telali (2007), World monthly means database project, Publ. Inst. Geophys. Pol. Acad. Sci., 99, 398.

Currie, R. G. (1973), Geomagnetic line spectra-2 to 70 years, Astrophys. Space Sci., 21(2), 425-438.

Delouis, H., and P. N. Mayaud (1975), Spectral analysis of the geomagnetic activity index aa over a 103-year interval, J. Geophys. Res., 80, 4681-4688, doi:10.1029/JA080i034p04681.

Elias, A. G., and M. Zossi de Artigas (2008), The Quasi-Biennial Oscillation in Time Series of Solar Activity Parameters, Solar Phys. Res. Trends, edited by P. Wang, pp. 3-13, Nova Publ., New York.

Fejer, B. G., and L. Scherliess (1995), Time dependent response of equatorial ionospheric electric fields to magnetospheric disturbances, Geophys. Res. Lett., 22, 851-854, doi:10.1029/95GL00390.

Finlay, C. C., V. Lesur, E. Thébault, F. Vervelidou, A. Morschhauser, and R. Shore (2016), Challenges handling magnetospheric and ionospheric signals in internal geomagnetic field modelling, Space Sci. Rev., 1-33.

Fraser-Smith, A. C. (1972), The spectrum of the geomagnetic activity index Ap, J. Geophys. Res., 77, 4209-4220, doi:10.1029/ JA077i022p04209

Gauss, C. F. (1839), Allgemeine theorie des erdmagnetismus, Resultate aus den Beobachtungen des magnetischen Vereins im Jahre, 1838, 1-57. Gillet, N., D. Jault, E. Canet, and A. Fournier (2010), Fast torsional waves and strong magnetic field within the Earth's core, Nature, $465,74-77$. Holappa, L., K. Mursula, T. Asikainen, and I. G. Richardson (2014), Annual fractions of high-speed streams from principal component analysis of local geomagnetic activity, J. Geophys. Res. Space Physics, 119, 4544-4555, doi:10.1002/2014JA019958.

Howe, R., J. Christensen-Dalsgaard, F. Hill, R. W. Komm, R. M. Larsen, J. Schou, M. J. Momptson, and J. Toomre (2000), Dynamic variations at the base of the solar convection zone, Science, 287(5462), 2456-2460.

lijima, T. (2000), Field-aligned currents in Geospace: Substance and significance, in Magnetospheric Current Systems, pp. 107-129, AGU, Washington, D. C.

Jordanova, V. K., A. Boonsiriseth, R. M. Thorne, and Y. Dotan (2003), Ring current asymmetry from global simulations using a high-resolution electric field model, J. Geophys. Res., 108(A12), 1443, doi:10.1029/2003JA009993.

Kalinin, Y. D. (1954), The long period geomagnetic variation, Handbook of the Variable Magnetic Field in the USSR, Res. Inst. for Terr. Magn. Leningrad. (Translated by E. R. Hope: DRB manuscript T 379 R).

Kamide, Y., and S. Kokubun (1996), Two-component auroral electrojet: Importance for substorm studies, J. Geophys. Res., 101, 13,027-13,046, doi:10.1029/96JA00142.

Kane, R. P. (1997), Quasi-biennial and quasi-triennial oscillations in geomagnetic activity indices, Ann. Geophys., 15(12), $1581-1594$.

Kane, R. P. (2005), Differences in the quasi-biennial oscillation and quasi-triennial oscillation characteristics of the solar, interplanetary, and terrestrial parameters, J. Geophys. Res., 110, A01108, doi:10.1029/2004JA010606.

Katsavrias, C., P. Preka-Papadema, and X. Moussas (2012), Wavelet analysis on solar wind parameters and geomagnetic indices, Sol. Phys., 280(2), 623-640.

Kudela, K., J. Rybák, A. Antalová, and M. Storini (2002), Time evolution of low-frequency periodicities in cosmic ray intensity, Sol. Phys., 205(1), $165-175$.

Langel, R. A., R. H. Estes, G. D. Mead, E. B. Fabiano, and E. R. Lancaster (1980), Initial geomagnetic field model from Magsat vector data, Geophys. Res. Lett., 7, 793-796, doi:10.1029/GL007i010p00793.

Laurenza, M., M. Storini, S. Giangrave, and G. Moreno (2009), Search for periodicities in the IMP 8 charged particle measurement experiment proton fluxes for the energy bands 0.50-0.96 MeV and 190-440 MeV, J. Geophys. Res., 114, A01103, doi:10.1029/2008JA013181.

Le, G., C. T. Russell, and K. Takahashi (2004), Morphology of the ring current derived from magnetic field observations, Ann. Geophys., 22(4), 1267-1295.

Lesur, V., I. Wardinski, M. Rother, and M. Mandea (2008), GRIMM: The GFZ reference internal magnetic model based on vector satellite and observatory data, Geophys. J. Int., 173(2), 382-394.

Lockwood, M., R. Stamper, and M. N. Wild (1999), A doubling of the Sun's coronal magnetic field during the past 100 years, Nature, 399(6735), 437-439.

Lowes, F. (2007), Geomagnetic spectrum, spatial, in Encyclopedia of Geomagnetism and Paleomagnetism, pp. 350-353, Springer, Netherlands.

Lukianova, R., K. Mursula, and A. Kozlovsky (2012), Response of the polar magnetic field intensity to the exceptionally high solar wind streams in 2003, Geophys. Res. Lett., 39, L04101, doi:10.1029/2011GL050420.

Lyon, J. G. (2000), The solar wind-magnetosphere-ionosphere system, Science, 288(5473), 1987-1991.

Mandea, M., R. Holme, A. Pais, K. Pinheiro, A. Jackson, and G. Verbanac (2010), Geomagnetic jerks: Rapid core field variations and core dynamics, Space Sci. Rev., 155(1-4), 147-175.

Malin, S. R. C., and B. M. Hodder (1982), Was the 1970 geomagnetic jerk of internal or external origin?, Nature, 296, 726-728.

Mursula, K., and J. H. Vilppola (2004), Fluctuations of the solar dynamo observed in the solar wind and interplanetary magnetic field at 1 AU and in the outer heliosphere, Sol. Phys., 221(2), 337-349.

Mursula, K., and B. Zieger (2000), The 1.3-year variation in solar wind speed and geomagnetic activity, Adv. Space Res., 25(9), 1939-1942.

Mursula, K., B. Zieger, and J. H. Vilppola (2003), Mid-term quasi-periodicities in geomagnetic activity during the last 15 solar cycles: Connection to solar dynamo strength-To the memory of Karolen I. Paularena (1957-2001), Sol. Phys., 212(1), $201-207$.

Newell, P. T., K. Liou, J. W. Gjerloev, T. Sotirelis, S. Wing, and E. J. Mitchell (2016), Substorm probabilities are best predicted from solar wind speed, J. Atmos. Sol. Terr. Phys., 146, 28-37.

Olsen, N. (1994), A 27-month periodicity in the low latitude geomagnetic field and its connection to the stratospheric QBO, Geophys. Res. Lett., 21, 1125-1128, doi:10.1029/94GL00180.

Olsen, N., H. Lühr, T. J. Sabaka, M. Mandea, M. Rother, L. Tøffner-Clausen, and S. Choi (2006), CHAOS-A model of the Earth's magnetic field derived from CHAMP, Ørsted, and SAC-C magnetic satellite data, Geophys. J. Int., 166(1), 67-75.

Olsen, N., K. H. Glassmeier, and X. Jia (2010), Separation of the magnetic field into external and internal parts, Space Sci. Rev., 152, 135-157.

Olsen, N., et al. (2015), The Swarm initial field model for the 2014 geomagnetic field, Geophys. Res. Lett., 42, 1092-1098, doi:10.1002/ 2014GL062659. 
Ou, J., N. Gillet, and A. Du (2015), Geomagnetic observatory monthly series, 1930 to 2010: Empirical analysis and unmodeled signal estimation, Earth Planets Space, 67(1), 1-20.

Paularena, K. I., A. Szabo, and J. D. Richardson (1995), Coincident 1.3-year periodicities in the ap geomagnetic index and the solar wind, Geophys. Res. Lett., 22, 3001-3004, doi:10.1029/95GL02802.

Rangarajan, G. K. (1985), Quasi-biennial oscillation in geomagnetic disturbance field, Proc. Indian Acad. Sci. Earth Planet. Sci., 94(1), 29-34.

Rao, K. R., and K. T. Joseph (1971), Quasi-biennial oscillation in the geomagnetic Sq field in the low latitude region, J. Atmos. Terr. Phys., 33(5), 797-805.

Reed, R. J. (1965), The quasi-biennial oscillation of the atmosphere between 30 and $50 \mathrm{~km}$ over Ascension Island, J. Atmos. Sci., 22(3), 331-333.

Reed, R. J., W. J. Campbell, L. A. Rasmussen, and D. G. Rogers (1961), Evidence of a downward-propagating, annual wind reversal in the equatorial stratosphere, J. Geophys.Res., 66, 813-818, doi:10.1029/JZ066i003p00813.

Richardson, I. G., E. W. Cliver, and H. V. Cane (2000), Sources of geomagnetic activity over the solar cycle: Relative importance of coronal mass ejections, high-speed streams, and slow solar wind, J. Geophys. Res., 105, 18,203-18,213, doi:10.1029/1999JA000400.

Ruzmaikin, A., A. C. Cadavid, and J. Lawrence (2008), Quasi-periodic patterns coupling the Sun, solar wind and the Earth, J. Atmos. Sol.-Terr. Phys., 70(17), 2112-2117.

Sakurai, K. (1979), Quasi-biennial variation of the solar neutrino flux and solar activity, Nature, 278, 146-148.

Silva, L., L. Jackson, and J. Mound (2012), Assessing the importance and expression of the 6 year geomagnetic oscillation, J. Geophys. Res., 117 B10101, doi:10.1029/2012JB009405.

Silverman, S. M., and R. Shapiro (1983), Power spectral analysis of auroral occurrence frequency, J. Geophys. Res., 88, 6310-6316, doi:10.1029/ JA088iA08p06310.

Stacey, F. D., and P. Westcott (1962), Possibility of a 26-or 27-month periodicity in the equatorial geomagnetic field and its correlation with stratospheric winds, Nature, 196, 730-732.

Stamper, R., M. Lockwood, M. N. Wild, and T. D. G. Clark (1999), Solar causes of the long-term increase in geomagnetic activity, J. Geophys. Res., 104, 28,325-28,342, doi:10.1029/1999JA900311.

Stening, R. J. (2008), The shape of the Sq current system, Ann. Geophys., 26(7), 1767-1775.

Sugiura, M. (1976), Quasi-biennial geomagnetic variation caused by the Sun, Geophys. Res. Lett., 3, 643-646, doi:10.1029/GL003i011p00643.

Sugiura, M., and D. J. Poros (1977), Solar-generated quasi-biennial geomagnetic variation, J. Geophys. Res., 82, 5621-5628, doi:10.1029/ JA082i035p05621.

Svalgaard, L., and E. W. Cliver (2007), Interhourly variability index of geomagnetic activity and its use in deriving the long-term variation of solar wind speed, J. Geophys. Res., 112, A10111, doi:10.1029/2007JA012437.

$\mathrm{Xu}$, W. Y., and Y. Kamide (2004), Decomposition of daily geomagnetic variations by using method of natural orthogonal component, J. Geophys. Res., 109, A05218, doi:10.1029/2003JA010216.

Xu, W. Y., G. X. Chen, A. M. Du, Y. Y. Wu, B. Chen, and X. C. Liu (2008), Key points model for polar region currents, J. Geophys. Res., 113, A03S11, doi:10.1029/2007JA012588.

Yacob, A., and B. N. Bhargava (1968), On 26-month periodicity in quiet-day range of geomagnetic horizontal force and in sunspot number, J. Atmos. Terr. Phys., 30(11), 1907-1911.

Zhao, X. D., A. M. Du, and W. Y. Xu (2013), The magnetic local time distribution of ring current during the geomagnetic storm, Planet. Space Sci., 78, 52-63. 